
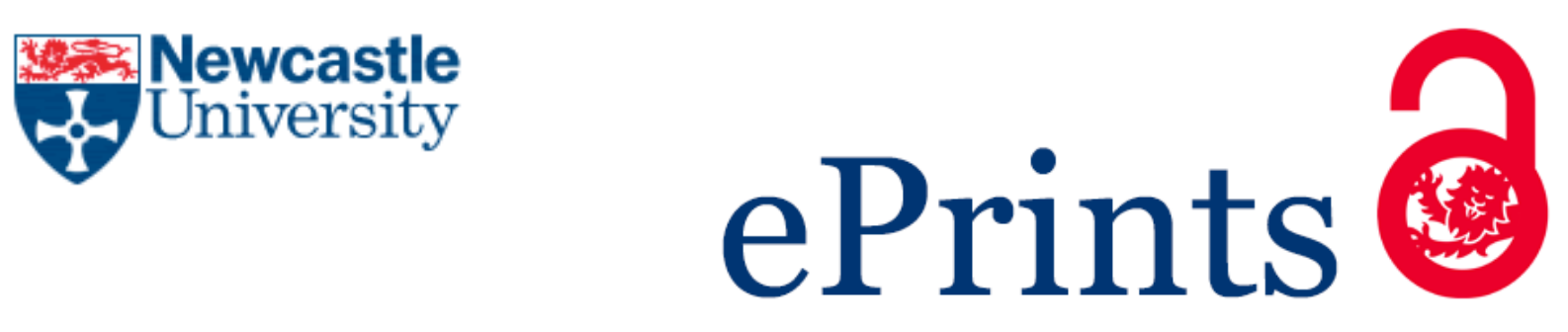

Lambert SM, Mecrow BC, Abebe R, Vakil G, Johnson CM. Integrated drives for transport - A review of the enabling electronics technology. In: Vehicle Power and Propulsion Conference (VPPC), 2015 IEEE. 2015, Montréal, Canada: IEEE.

\title{
Copyright:
}

(C) 2015 IEEE. Personal use of this material is permitted. Permission from IEEE must be obtained for all other uses, in any current or future media, including reprinting/republishing this material for advertising or promotional purposes, creating new collective works, for resale or redistribution to servers or lists, or reuse of any copyrighted component of this work in other works.

DOI link to article:

http://dx.doi.org/10.1109/VPPC.2015.7352967

Date deposited:

$06 / 01 / 2016$ 


\section{Integrated drives for transport - A review of the enabling electronics technology}

\author{
Simon M. Lambert, Barrie C. Mecrow \\ School of Electrical and Electronic Engineering \\ Merz Court, Newcastle University \\ Newcastle upon Tyne, United Kingdom
}

\begin{abstract}
The space and packaging constraints for various electric transport applications such as for electric and hybrid electric vehicles or mass transit systems ultimately require that electronic and mechanical subsystems become more fully integrated. This paper outlines the current state of art for the power electronic converter technologies which enables greater integration in electric drives. Investigations into the supply options, state of the art devices, switching frequency selection, filtering requirements and system modularity options are explored and future trends are discussed.
\end{abstract}

Keywords-Integrated drive

\section{INTRODUCTION}

INTEGRATED drives are increasingly being regarded as the logical future for many electric drives - particularly in applications where space is at a premium such as transport. Consisting of the combination mechanical, thermal and electrical aspects of an electric drive system integrated drives have been proposed in literature claiming to exhibit significant benefits over traditional electrical drive systems [1-12] as well as cost reductions of $20-40 \%$ [35]. The key technical advantages in using an integrated drive versus a traditionally packaged drive can be summarized by these points;

-Volume/mass reduction over traditional separately constructed systems

-Possible reduced EMC problems due to elimination of cables transferring power at high frequency

-The ability to replace direct online machines with variable speed machines without significantly altering the associated plant

-Single package installation - reduced installation time/cost

-Integrated or common cooling reducing hose lengths and chiller sizes

- Greater flexibility in the machine and drive topologies from greater design synergy

Although a significant number of publications and commercial prototypes are widely known about integrated drives as a technological concept it is not a mature technology. Indeed, there is significant evidence that the state of the art in integrated drive technology will be bolstered by emerging technologies such as wide bandgap devices and high temperature passives. There is therefore, a justifiable interest

\author{
Robert Abebe, Gaurang Vakil, C. Mark Johnson \\ Department of Electrical and Electronic Engineering \\ University Park, University of Nottingham \\ Nottingham, United Kingdom
}

in benchmarking the current state of emerging converter technologies which, it is envisaged, will drive the development of future integrated drives.

Broadly, an electric drive can be considered to consist of all equipment which is located between the electrical supply and the mechanical output of an actuator. Common examples are variable speed drives in applications such as pumps, electric vehicle drivetrains, renewable energy generators, aircraft actuators, mass transit traction, air conditioning units and many more. The supply may be a standard three phase industrial supply, single phase domestic or a DC power network or from more specialized applications such as an aircraft power network. The actuator in an electric drive is commonly a rotating machine however linear actuators may also be considered. A gearbox may also be incorporated into the drivetrain to regulate the actuator. However, since where they are used gearboxes are generally well integrated to the machine, gearbox integration is not considered in this review.

The nature of the actuators employed in electric drives is very diverse and may consist of one of a number of machine types. Since, in variable speed drives, the supply characteristics rarely match the requirements of the actuator it is usual for a power electronic converter to provide an interface between the supply and the actuator. The power electronic converter consists of main power devices - the power switches - and their associated driving, sensing and control electronics. Again, there is significant variance in the topology of the power electronic converter for electric drives as they can perform a number of functions.

Filter and other passive components are also integral parts of most electric drives enabling compliance with issues such as EMC and imposed supply harmonic limitations.

In most applications the power electronic components and the electrical actuator are considered physically separate entities with their mechanical and thermal design aspects approached in isolation. The result of this is that the power electronic converter and the actuator are usually packaged individually and installed separately. Figure 1 shows an example of a pair of traditional variable frequency drives in a cabinet mounting with their associated electrical machines installed in such an arrangement. 


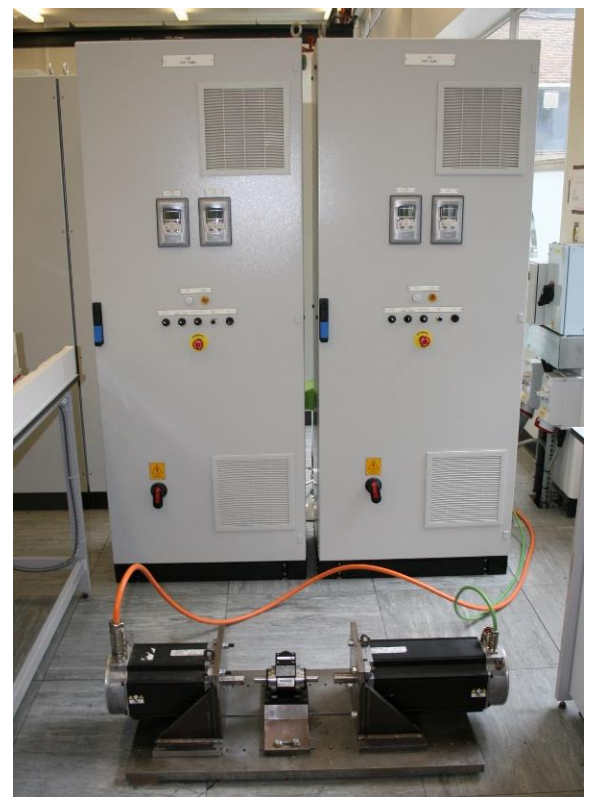

Figure 1 - Standard cabinet-based packaging of a variable speed drive

Clearly, there are aspects of the packaging and mechanical management which are common to both the actuator and converter and it may therefore be desirable to combine the physical construction of the whole drive in order to remove duplication and reduce the space envelope of the system as a whole. Figure 2 shows an example of an integrated drive from literature.

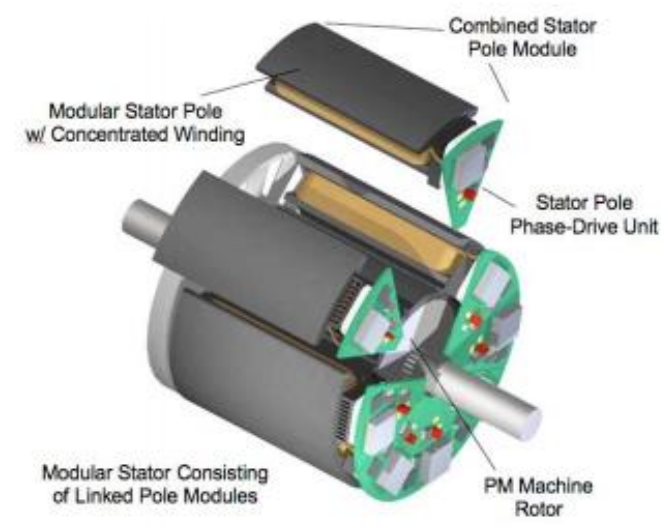

Figure 2 - An example of an integrated drive from literature (2.7kW, OD $=120 \mathrm{~mm})[7]$

\section{ELECTRICAL CONSIDERATIONS}

In an integrated drive the power electronic converter and the machine are designed and developed simultaneously. This gives the process far greater flexibility than in traditional circumstances whereby a drive may be designed for an unknown machine topology and vice versa. In this context the standard limitations such as phase number or machine voltage become part of the design optimization process. Less conventional electrical topologies for both the machine windings and the power electronic converter can be considered.

\section{A. Supply considerations}

The electrical design of any drive is heavily dependent on the available supply. Industrial drives are commonly supplied via standard three phase electricity mainly at levels between 380 and 480V (depending on geographic location). A variable speed drive supplied in this manor usually consists of a rectifier, or $\mathrm{AC}$ to $\mathrm{DC}$, portion followed by an inverter, or DC to $\mathrm{AC}$, section although exceptions such as matrix converters [6] are also well known.

For AC supplies there is significant variation in the topology and current characteristics of the drive. The drive rectifier stage often consists of a simple six-diode bridge rectifier. In addition [14] describes a further sixteen topologies specifically compared for integrated drives. The treatment of AC supply current by the drive can broadly be split into three categories; the first, with square wave input current waveforms, utilize a passive diode based rectifier. Some topologies also include an intermediate converter between the rectifier and the DC link capacitor in order to regulate the current flow into to DC link capacitor. This category offers reduced total harmonic distortions (THD) (to about 30\%), greater robustness to supply phase imbalance and reduced filter sizing compared to a standard bridge rectifier topology [14].

The two further categories of AC supply treatment concern controlled sinusoidal input currents in both mono-directional and bi-directional power flow formats. With these innovations the THD of the input current can be reduced as low as $7 \%$ of that of the original diode rectifier.

If the drive is only required to operate as a load then sinusoidal input current is realizable in a number of topologies such as DCM boost, Vienna, or multi-level rectifiers [15, 16]. A standard back-to-back H-bridge rectifier/inverter is well known as a standard topology for AC fed variable speed drives where bi-directional power is required. Other front-end topologies have been proposed to allow bi-directional conversion from an AC supply such as matrix converters [6] or multi-level rectifiers utilizing reverse blocking semiconductors [16]. Some of these more unusual topologies have been identified to produce smaller losses and lower overall volume when considering the boost inductance of the standard back-to-back converter [14].

In many mobile applications such as for $(\mathrm{H}) \mathrm{EVs}$ and battery powered portable appliances or for situations where the drive is fed from a DC network such as in micro-grids as found on electric shipping or on an aircraft the supply to the drive is often DC. In these situations there is obviously no 
need for a rectifier component to the front-end of the drive. There may still, however, be strict restrictions on the quality of the current profile drawn from the supply [17].

\section{B. Conversion type}

In addition to the type of supply covered in the above the level, variability of the supply is also an important design consideration. It is desirable in all drives applications, but particularly in integrated drives where the thermal coupling of the assembled power electronics and machine is high, to reduce the power electronics losses as much as possible. The operating voltage of the converter dictates much of the loss characteristics since both switching and conduction loss are functions of the operating voltage. It may therefore pay dividends to operate at a boosted voltage to reduce conduction loss whilst using devices with faster switching characteristics to offset the increased switching loss. Higher voltage output voltages from the drive will also allow for a faster rotation speed for a given machine increasing output power for no change in volume - it must be noted that the machine must be mechanically capable of the increased speed for safe operation.

\section{Switching frequency}

The general trend in variable speed drives over recent history is that of increasing switching frequency. Higher frequency switching has a number of advantages allowing better tracking of input and output waveforms reducing THD, and allowing better transient response. In traditional silicon drives in the order of tens of $\mathrm{kW}$ the switching frequency has been limited to $<20 \mathrm{kHz}$ [18] because of the switching loss. Advances in silicon-carbide and gallium-nitride devices capable of much higher switching rates are challenging this limitation with tens of $\mathrm{kW}$ drives operating upwards of 100 $\mathrm{kHz}$ [19]. The lower distortions of input and output current reduce the amount of filtering that is required to comply with harmonic quality constraints.

Increased frequency operation does however induce electromagnetic radiation and emission at higher frequency creating more EMI issues [20].

\section{Output requirements}

Since the integrated drive design process combines the design of both the variable speed drive and the machine no assumptions are necessary regarding the drive output. Most sinusoidal variable speed machines operate on three phases, partially a hangover from direct-online-starting machines but mainly because having a standard phase number suits the interchangeability of machines and drives.

Increased phase number can offer some advantages when considering the physical drive layout. In [7] the drives are segmented into identical inverter legs and laid out on the machine in a rotationally symmetric manor on one endplate, thus to distribute the power density and therefore loss density more evenly over the endplate. This modularity clearly has advantages for the manufacturing and maintenance processes in that smaller identical drive elements are required to be installed or replaced. A higher number of output phases also reduces the ripple on the DC link decreasing the filtering requirements which can reduce the size of the DC link capacitor.

Extending the number of phases to encompass multiple electrical machines within a single mechanical package lends itself well to fault tolerance [21-23].

For non-sinusoidal machines such as brushless permanent magnet (BPM) or switched reluctance machines (SRM) increased phase number has advantages in the quality of the output torque as well as ripple on the DC link.

The frequency and amplitude of the DC link ripple is a function of the number of output phases of the drive. Since the required size of the DC link capacitor is directly linked to the level of DC current ripple then reducing the ripple is desirable in order to reduce the size of the DC link capacitors which are commonly the largest single component in the drive. There is therefore a volume, if not cost, analysis to be done in increasing the phase number, thus increasing the number of active devices in the drive but crucially decreasing the much physically larger capacitor requirement. Naturally varying the phase number of the drive has strong implications on the design of the machine and could only reasonably considered when designing the drive and machine in tandem.

\section{E. Modularity}

A number of publications have reported exploitation of the modularity of a polyphase system within the context of an integrated drive $[7,12]$. The key advantages of this modularity cited as manufacturing commonalities, fault tolerant operation/better fault management and ease of maintenance.

The distributed nature of the drive becomes an issue when considering common components such as the DC link capacitor. The parasitic inductance which is a result of distributing the DC filter across a number of modules is described in some detail in [7].

Segmented stators with concentrated winding configurations are also discussed yielding manufacturing advantages in that it is much easier to wind over a single tooth. Some configurations also have removable teeth increasing the manufacturability yet further [24]. The disadvantage of single tooth windings is the inherent issues they create with harmonic distortion of the machine's torque profile [25]. 


\section{F. Wide bandgap devices}

In recent years wide bandgap devices, which for a long time were not commercially viable for high volume drives, are becoming increasingly available relatively readily at lower costs. The advantage of wide bandgap devices is that they are able to switch at far higher frequencies due to the higher electron mobility and larger bandgap energy compared to traditional $\mathrm{Si}$ devices [36]. $\mathrm{SiC}$ is the more commercially developed technology with a wider variety of manufacturers and individual devices available however while $\mathrm{SiC}$ has higher electron mobility than $\mathrm{Si}$, GaN's electron mobility is higher than $\mathrm{SiC}$ meaning that $\mathrm{GaN}$ should ultimately be the best device to provide lower losses at higher frequencies [37].

Although this being the case $\mathrm{SiC}$ poses some significant advantages over GaN (other than its commercial readiness) in power device application for a number of reasons. In particular, the cost of manufacturing $\mathrm{GaN}$ wafers is significantly higher and the yield is known to be poorer.

\section{G. Filter requirements}

For most drives, particularly those with active front end rectifiers, there is a requirement for a line-side filter in order to reduce harmonic distortion on the supply. Regulations may exist to protect the public power network from excessive harmonics, or as part of wider EMC regulations. Although the category of 'low frequency' for EMC standards extends officially up to $9 \mathrm{kHz}$, in most cases only harmonics up to order 50 are considered, which is $2.5 \mathrm{kHz}$ on a $50 \mathrm{~Hz}$ supply and $3 \mathrm{kHz}$ on a $60 \mathrm{~Hz}$ supply. There are currently no limits to emission in the range from $2.5 \mathrm{kHz} / 3 \mathrm{kHz}$ to $9 \mathrm{kHz}$ [18]. Many active front end converters also include a boost section for better utilization of the active devices. The size of the input inductance is therefore heavily dependent on the operation mode of the input rectifier. Indeed, the topology of a boosted input rectifier greatly effects the size of the boost inductor varying from $31 \%$ to $10 \%$ of the total volume of the drive enclosure [14]. In general, it has been reported that the voltage drop across the input filter inductor for a diode rectified frontend represents around $2 \%$ of the total input line voltage, values higher than this need to be approached with caution as the drive input voltage begins to tail off significantly [18].

The output cable for an electric drive can cause issues both with EMC and voltage doubling effect due high $\mathrm{dV} / \mathrm{dt}$ of the output. A high $\mathrm{dV} / \mathrm{dt}$ for the converter is desirable for a number of reasons; reduced switching loss, lower distortion due to switching transients, reduced amount of required dead time and it also allows increased switching frequency [26].

Voltage doubling occurs because of mismatch between the wave impedances of the inverter output, cable and machine terminals. The effect, as the name suggests, results in the voltage on the motor terminals doubling at each switching transient once cable length exceeds a certain limit. The critical cable length $\left(l_{c}\right)$ can be calculated based on the maximum $\mathrm{dV} / \mathrm{dt}$ on the inverter output, the critical values given in [27] have been used to derive an expression for the critical length;

$$
l_{c} \geq 5 \times 10^{10}\left[\frac{\Delta V}{\Delta t}\right]^{-1}
$$

where $\frac{\Delta V}{\Delta t}$ is the rate of change of voltage on the drive output during a switching transient in V/s.

For a modern $\mathrm{SiC}$ module with $\mathrm{V}_{\mathrm{DC}}=600 \mathrm{~V}, \mathrm{I}_{\mathrm{d}}=120 \mathrm{~A}$ the $\mathrm{dV} / \mathrm{dt}$ has been measured at anything from 2.5 to $25 \mathrm{~V} / \mathrm{ns}$ (depending on the gate resistor) [28]. This would give a maximum length of cable less than $2 \mathrm{~m}$. Considering this length must be considered as the entire conduction length between the transistors and the motor terminals this does not lend itself well to a separately packaged drive and machine. There has been considerable effort in designing output filters for drives to eliminate the high frequency content of the drive output [29-33]. In order to reduce the complexity (and size) of the drive it is desirable to omit these filters. Thus the required proximity of a high switching frequency drive without the output filter to the machine encourages integrated packaging.

Where intermediate magnetics, such as boost inductors, are employed in relation to very high frequency switching $(>100 \mathrm{kHz})$ round conductors have significantly increased loss due to eddy current effect. Therefore, for such components utilizing planar magnetics yields considerable advantages both in loss and packaging. Indeed, the height of a planar component is generally $25-50 \%$ of the height of the wirewound counterpart [34].

Other passive components, in particular input and DC link capacitors, form a large part of the drive's volume and cost. Capacitors especially have poor thermal performance and have traditionally been packed in such a way as to make congruent packaging difficult - such as cylindrical packaging.

Capacitors in electric drives are commonly either multilayer ceramic, electrolytic or film capacitors. Multi-layer ceramic capacitors have high capacitances per volume and offer very high AC current ratings and temperature operation [38].

Electrolytic capacitors are commonly the cheapest capacitor option. They are a polarized device and offer poor AC current ratings with a lower maximum temperature rating. They also have a low maximum voltage which is in practice about 600V [39].

Film capacitors offer the most flexibility, they are capable of operating at very high voltages (multi $\mathrm{kV}$ ) with relatively 
low AC loss. They have considerably better life spans than electrolytic capacitors and more commonly used in high frequency drives.

\section{CONCLUSION}

Integrated drives have been presented in past literature as the logical culmination of the integration of drive technology for a number of modern applications. The advantages in reduction of volume and mass, EMI reduction, control flexibility and general miniaturization of the drive are well documented.

Integrating the converter with the machine gives a far greater flexibility in design options through converter topologies, phase number and voltage levels. The ability to utilize the high switching capabilities of wide bandgap devices and modern capacitor technology allows faster, less harmonically challenged, drives to operate with smaller filters.

This paper has outlined the recent research advances which yield technologies which can be exploited by an integrated drive design in order to improve electrical, performance.

Integrated drives would still not be considered a mature technology area and given the advances constantly being made on the technologies reported in this paper it is perceived that integrated drive technology will continue to evolve over the coming years. Almost certainly the penetration of wide bandgap devices will be divisive in how electric drives, integrated or not, are designed in the future. Passives which are packaged for integration with modules are already increasing the power densities which are achievable and more modular structures are enabling scalable designs with common interconnect ability.

\section{ACKNOWLEDGMENT}

This work was supported by the Engineering and Physical Sciences Research Council (EPSRC) Centre for Power Electronics (Grant references: EP/K035304/1, EP/K034987/1)

\section{REFERENCES}

[1] F. Farina, D. Rossi, A. Tenconi, F. Profumo, and S. E. Bauer, "Thermal design of integrated motor drives for traction applications," in Power Electronics and Applications, 2005 European Conference on, 2005, pp. 10 pp.-P.10.

[2] A. Tenconi, F. Profumo, S. E. Bauer, and M. D. Hennen, "Temperatures Evaluation in an Integrated Motor Drive for Traction Applications," Industrial Electronics, IEEE Transactions on, vol. 55, pp. 3619-3626, 2008.

[3] M. Gerber and M. Marz, "System integration in automotive power systems," in Power Electronics and Applications, 2005 European Conference on, 2005, pp. 10 pp.-P.10.

[4] M. Ektesabi and H. Felic, "Controlling Heat, Vibration and EMI in an Integral Motor," in Compatibility in Power Electronics, 2007. CPE '07, 2007, pp. 1-5.
[5] S. Pickering, F. Thovex, P. Wheeler, and K. Bradley, "Thermal Design of an Integrated Motor Drive," in IEEE Industrial Electronics, IECON 2006 - 32nd Annual Conference on, 2006, pp. 4794-4799.

[6] P. Wheeler, J. C. Clare, M. Apap, D. Lampard, S. Pickering, K. J. Bradley, et al., "An Integrated 30kW Matrix Converter based Induction Motor Drive," in Power Electronics Specialists Conference, 2005. PESC '05. IEEE 36th, 2005, pp. 2390-2395.

[7] N. R. Brown, T. M. Jahns, and R. D. Lorenz, "Power Converter Design for an Integrated Modular Motor Drive," in Industry Applications Conference, 2007. 42nd IAS Annual Meeting. Conference Record of the 2007 IEEE, 2007, pp. 1322-1328.

[8] Y. Shakweh, G. H. Owen, D. J. Hall, and H. Miller, "Plug and play integrated motor drives," in Power Electronics, Machines and Drives, 2002. International Conference on (Conf. Publ. No. 487), 2002, pp. 655-661.

[9] S. Gui-Jia, T. Lixin, C. Ayers, and R. Wiles, "An inverter packaging scheme for an integrated segmented traction drive system," in Energy Conversion Congress and Exposition (ECCE), 2013 IEEE, 2013, pp. 2799-2804.

[10] N. C. Harris, T. M. Jahns, and H. Surong, "Design of an integrated motor/controller drive for an automotive water pump application," in Industry Applications Conference, 2002. 37th IAS Annual Meeting. Conference Record of the, 2002, pp. 2028-2035 vol.3.

[11] W. Jiyao, L. Ye, and H. Yehui, "Evaluation and design for an integrated modular motor drive (IMMD) with GaN devices," in Energy Conversion Congress and Exposition (ECCE), 2013 IEEE, 2013, pp. 4318-4325.

[12] J. J. Wolmarans, M. B. Gerber, H. Polinder, S. W. H. de Haan, J. A. Ferreira, and D. Clarenbach, "A $50 \mathrm{~kW}$ integrated fault tolerant permanent magnet machine and motor drive," in Power Electronics Specialists Conference, 2008. PESC 2008. IEEE, 2008, pp. 345-351.

[13] S. Kocman, Orsa, x, and P. g, "Efficiency evaluation of various assemblies of variable speed drive," in Environment and Electrical Engineering (EEEIC), 2014 14th International Conference on, 2014, pp. 360-364.

[14] C. Klumpner, F. Blaabjerg, and P. Thogersen, "Evaluation of the converter topologies suited for integrated motor drives," in Industry Applications Conference, 2003. 38th IAS Annual Meeting. Conference Record of the, 2003, pp. 890-897 vol.2.

[15] J. W. Kolar and H. Ertl, "Status of the techniques of three-phase rectifier systems with low effects on the mains," in Telecommunication Energy Conference, 1999. INTELEC '99. The 21st International, 1999, p. $16 \mathrm{pp}$.

[16] C. Klumpner and F. Blaabjerg, "Using reverse-blocking IGBTs in power converters for adjustable-speed drives," Industry Applications, IEEE Transactions on, vol. 42, pp. 807-816, 2006.

[17] C. Zhong, W. Zhihui, W. Changyou, and C. Miao, "Input Ripple Current Characteristics of Aviation Static Inverter," Aerospace and Electronic Systems, IEEE Transactions on, vol. 49, pp. 1667-1676, 2013.

[18] B. Drury, "The control techniques drives and controls handbook," 2009.

[19] S. Amano and K. Akatsu, "Study on high frequency inverter with $100 \mathrm{kHz}$ current feedback control by using FPGA," in Electrical Machines and Systems (ICEMS), 2014 17th International Conference on, 2014, pp. 3392-3397.

[20] M. Degano, P. Zanchetta, L. Empringham, E. Lavopa, and J. Clare, "HF induction motor modeling using automated experimental impedance measurement matching," Industrial Electronics, IEEE Transactions on, vol. 59, pp. 3789-3796, 2012.

[21] J. W. Bennett, G. J. Atkinson, B. C. Mecrow, and D. J. Atkinson, "Fault-Tolerant Design Considerations and Control Strategies for 
Aerospace Drives," Industrial Electronics, IEEE Transactions on, vol. 59, pp. 2049-2058, 2012.

[22] C. Wenping, B. C. Mecrow, G. J. Atkinson, J. W. Bennett, and D. J. Atkinson, "Overview of Electric Motor Technologies Used for More Electric Aircraft (MEA)," Industrial Electronics, IEEE Transactions on, vol. 59, pp. 3523-3531, 2012.

[23] J. W. Bennett, B. C. Mecrow, A. G. Jack, and D. J. Atkinson, "A Prototype Electrical Actuator for Aircraft Flaps," Industry Applications, IEEE Transactions on, vol. 46, pp. 915-921, 2010.

[24] J. D. Widmer, C. M. Spargo, G. J. Atkinson, and B. C. Mecrow, "Solar Plane Propulsion Motors With Precompressed Aluminum Stator Windings," Energy Conversion, IEEE Transactions on, vol. 29, pp. 681-688, 2014.

[25] C. M. Spargo, B. C. Mecrow, J. D. Widmer, C. Morton, and N. J.Baker, "Design and Validation of a Synchronous Reluctance Motor With Single Tooth Windings," Energy Conversion, IEEE Transactions on, vol. PP, pp. 1-11, 2015.

[26] B. Florkowska, M. Florkowski, J. Roehrich, and P. Zydron, "The influence of PWM stresses on degradation processes in electrical insulation systems," in Electrical Insulation and Dielectric Phenomena (CEIDP), 2010 Annual Report Conference on, 2010, pp. 1-4.

[27] J. K. Steinke, "Use of an LC filter to achieve a motor-friendly performance of the PWM voltage source inverter," Energy Conversion, IEEE Transactions on, vol. 14, pp. 649-654, 1999.

[28] R. Semiconductor. (2014, SiC Power Devices and Modules, Application Note

[29] D. A. Rendusara and P. N. Enjeti, "An improved inverter output filter configuration reduces common and differential modes dv/dt at the motor terminals in PWM drive systems," Power Electronics, IEEE Transactions on, vol. 13, pp. 1135-1143, 1998.
[30] Y. Sozer, D. A. Torrey, and S. Reva, "New inverter output filter topology for PWM motor drives," Power Electronics, IEEE Transactions on, vol. 15, pp. 1007-1017, 2000.

[31] J. P. Strom, J. Korhonen, J. Tyster, and P. Silventoinen, "Active dV/dt New Output-Filtering Approach for Inverter-Fed Electric Drives," Industrial Electronics, IEEE Transactions on, vol. 58, pp. 3840-3847, 2011.

[32] R. M. Tallam, G. L. Skibinski, T. A. Shudarek, and R. A. Lukaszewski, "Integrated differential-mode and common-mode filter to mitigate the effects of long motor leads on AC drives," in Energy Conversion Congress and Exposition (ECCE), 2010 IEEE, 2010, pp. 838-845.

[33] R. M. Tallam, G. L. Skibinski, T. A. Shudarek, and R. A. Lukaszewski, "Integrated Differential-Mode and Common-Mode Filter to Mitigate the Effects of Long Motor Leads on AC Drives," Industry Applications, IEEE Transactions on, vol. 47, pp. 2075-2083, 2011.

[34] O. Ziwei and M. A. E. Andersen, "Overview of Planar Magnetic Technology\&\#x2014;Fundamental Properties," Power Electronics, IEEE Transactions on, vol. 29, pp. 4888-4900, 2014.

[35] M. Babb, F. Bartos, "Integrated Motor Drive Combinations," Control Engineering Europe, vol. 57, no. 21, pp. 66, 2001.

[36] T.P. Chow, V. Khemka, J. Fedison, N. Ramungul, K. Matocha, Y. Tang, R.J. Gutmann, "SiC and GaN Bipolar Power Devices", SolidState Electronics, vol. 44, no. 2, pp. 277-301, 2000

[37] U. Mishra, "Compound Semiconductors; GaN and SiC, Separating Fact From Fiction in both Research and Business" http://www.apecconf.org/wpcontent/uploads/2014/01/2_APEC2013Plenary_Compound _Semic onductors_GaN_SiC_Mishra_Transphorm.pdf Accessed Apr 10 ,

[38] Yano Research Institute, "Capacitor Market in Japan: Key Research Findings 2009," Yano Research Institute, Tokyo, Japan, Nov. 2009.

[39] M. Bramoulle, "Electrolytic or film capacitors", Industry Applications Conference, Thirty-Third IAS Annual Meeting, vol. 2, pp. 1138-1142, 1998. 